\title{
Research on the Problems and Countermeasures of Enterprise Financial Management under the Current Internet Economy
}

\author{
Yizhong Hu \\ University of Hong Kong, Hong Kong SAR 999077, China \\ Email:929415623@qq.com
}

\begin{abstract}
The application of Internet technology in the development of enterprises can effectively reflect the business sit-uation of enterprises. Through the Internet platform, enterprises can display their own advantages and specialties, realize the supply chain links all over the world, strengthen the development trend of business digitization, use the digital mode to enable their own management mode, give full play to the advantages of e-commerce, and put forward higher requirements for the internal financial management of enterprises. Therefore, we should make full use of the Internet and understand the Internet with the help of the Internet to improve the efficiency of financial management.
\end{abstract}

Keywords: Internet, enterprise, financial management

\section{Introduction}

The application of Internet technology in enterprise development can effectively reflect the actual and real situation of enterprises to the society. More importantly, it is a brand-new reform of the Internet from the inside out. The Internet can easily show the advantages and characteristics of an enterprise to the masses. It can also use the Internet as a platform to easily and freely realize the global supply chain links, strengthen the development trend of business digitization, use the digital mode to enable its own management mode and give full play to the advantages of e-commerce. Although the enterprise has been in a state of steady development, there are also some problems in the operation process. Therefore, the most important requirement of Internet environment work is to do a good job in financial management.

\section{Concept and characteristics of network financial model}

\subsection{Concept of network financial model}

The so-called network financial model is to use information technology and the Internet to connect all links and levels of the enterprise with the network, form an information chain centered on the financial department in the enterprise, realize the information integration of enterprise financial management, procurement management, production management, business management and warehouse management, and realize the information integration of all levels of the enterprise in the process of integration Centralized financial control of departments and other units. In the new environment, the Internet has been popularized all over the world, and the remote control and operation of enterprise financial management can be realized. For some large enterprises, it greatly simplifies the financial information flow link of the head office, offices and branches. It becomes very convenient for enterprise finance to realize remote operation with the help of information technology, so as to improve the utilization efficiency of enterprise funds.

\subsection{Characteristics of network financial model}

Network financial model is the key of enterprise financial management mode in the current e-commerce environment. It can not only integrate network and information technology and enterprise financial management, but also has strong adaptability. It can develop new financial management mode in the enterprise. The characteristics of network financial model are mainly shown in the following aspects:

(1) Network financial information sharing

(2) Dynamic accounting

(3) Paperless treatment

(4) Cost control effectiveness

(5) Effective control of financial and operational risks

(6) Provide decision information 


\section{Basic conception of financial reengineering strategy}

In the establishment of enterprise reengineering strategy, enterprises need to reengineer their financial organization in order to better ensure the timeliness of financial management and seize the opportunity. It includes organizational structure reengineering and organizational management reengineering. From the perspective of management, the first thing an enterprise should do is to reengineer its financial system and organizational structure; The second is the reconstruction of financial mechanism. From the organizational and institutional level, enterprises must recycle the financial personnel, financial status and external environment and enterprises. The establishment of enterprise financial reengineering model is mainly used for the actual working mode that can be comprehensively optimized in the financial field, so as to make its operation more flexible and reasonable, and actively innovate to the enterprise organizational structure.

\section{Countermeasures of financial management of an enterprise under internet information}

\subsection{Strengthening financial risk management}

The enterprise network financial model still uses the open IP / TCP protocol, which makes it easy to be stolen and monitored by the outside world in the actual operation process, and the enterprise financial information and business information can be leaked. Therefore, in the process of establishing the network financial model, enterprises should not only weigh the security and efficiency, properly set relevant checkpoints on the basis of ensuring the rapid operation of data, but also establish a professional network maintenance team in the enterprise, so as to check the network security periodically. In addition, the information-based financial model pays more attention to timeliness, which reduces the approval between various links and brings greater security problems.

\subsection{Change working mode}

The information of enterprise financial management under the financial mode has a specific working mode. Different from the traditional mode, people must complete the corresponding online business based on the system prompt. Therefore, the financial model through information is not only convenient for financial management, but also realizes the change of the working mode of financial personnel to a great extent. The change of the above working methods not only requires the financial operators to form a new working concept, but also needs to constantly improve their own knowledge structure and reserves. Therefore, great efforts need to be made.

\subsection{Break through the boundaries of time and space}

The most important advantage of the information-based financial model is that it can break through the boundary of traditional information financial transmission, gradually change the enterprise financial management from internal to external, and change the link management from micro management to macro management. Financial personnel do not need to connect in time and space, enterprise financial managers can be free at home. With the development of mobile Internet technology, the setting of enterprise financial network based on mobile phone customers will become the development trend in the future.

\section{Conclusion}

The traditional financial management model has defects, which hinders the improvement of management efficiency of group enterprises. Therefore, in the Internet environment, combined with internet information technology, optimize, transform and restructure the original financial and accounting institutions, establish a database center and develop management software. Finally, establish a financial management model suitable for enterprises and improve enterprise management efficiency. Ensure high-quality, high-level and efficient operation in the process of information input and output, so that the centralized financial management program can play the greatest role in assisting enterprise management.

\section{References}

[1] Gao Rong. Research on the countermeasures of enterprise financial management under the e-commerce environment [J]. Business Accounting. 2014, 08: 36-39.

[2] Ma Honglan. Discussion on enterprise financial management mode under "Internet+"[J]. Taxation Economics Research. 2015, 06: 92-94.

[3] Wang Yumei. Research on financial management strategies of group enterprises based on the Internet environment [J]. 
Finance and Economics (Academic Edition). 2015, 07: 217-218.

[4] Li Gang. Analysis of the innovation path of financial management mode under the Internet economy environment [J]. Contemporary Finance and Economics. 2012(11):162-163.

[5] Ho Geun Lee, Dong Hwam Cho, Seong Chul Lee. Impact of e-Business initiatives on firm value[J]. Electronic Commerce Research and Applications. 2002(1): 309-3 12.

[6] Marilyn Greenstexn, Todd M. Electronic Commerce: Security, Risk Management and Contr01. 2000.

[7] J Chen. Research on Informationization of Financial Management Based on E-Commerce[J]. Advanced Materials Research. 2011. 